\title{
Acerca del mecanismo de la función genital femenina
}

\author{
DR. BERNHARd ZONDEK \\ Jerusalén, Israel \\ IX Congreso Argentino de Obstetricia y Ginecología - 24-29 de octubre de 1955 \\ Buenos Aires, Argentina
}

La característica más notable de la función genital de la mujer es la menstruación o flujo sanguíneo periódico de origen uterino, y desde tiempos remotos se ha asociado este episodio con interpretaciones misteriosas. La base científica de la mestruación no fue dilucidada sino hasta en las décadas recientes, y hoy sabemos que la misma es la expresión de la función hormonal del ovario, el cual está bajo el control del lóbulo anterior de la hipófisis. La función ovárica es imposible sin el control hipofisario, y no puede haber menstruación sin función ovárica. La disgregacićn del endometrio durante la regla se produce únicamente en los primates, es decir, en la especie humana y en los antropoides y no en los otros mamíferos, lo que ya de por sí indica que ia expulsión del endometrio y la hemorragia no son indispensables para la implantación del óvulo. No se sabe por qué la menstruación se produce sólo en los primates ni tampoco cuál es su objeto, pero parece evidente que debe haber alguna razón que se desprende de la circunstancia de que la sangre de la menstruación difiere en forma característica de la sangre del resto del organismo. La sangre de la menstruación es la única en el cuerpo incapaz de coagularse. En 1920 observé otra caracteristica del flujo menstrual que lo diferencia del resto de la sangre, y es su hemólisis.

\section{¿Contiene el flujo menstrual una toxina especifica?}

El antiguo concepto de que la menstruación favorece la excreción de sustancias tóxicas ha recibido nuevo apoyo de las in- 
vestigaciones de Smith y Smith quienes hallaron que la sangre de la menstruación, y sobre todo su plasma, contiene una toxina letal para las ratas de poca edad, dentro de las 48 horas, aún en dosis tan pequeñas como de 0,05 a $0,2 \mathrm{~cm} 3$. acompañándose la muerte de cambios anatómicos característicos. Esta toxina también se encuentra en el endometrio al comienzo de la menstruación y parece ser una euglobulina atípica idéntica a la necrosina descrita por Menkin. Se supone que esta toxina tiene efecto decisivo en el mecanismo de la menstruación al producir la constricción de las arteriolas espiraladas iniciando así el flujo menstrual.

En años recientes hemos investigado en nuestro laboratorio el problema de la toxina menstrual, y en contraste con las observaciones de Smith y Smith, quienes hallaron que la sangre de la menstruación mataba las ratas en el $95 \%$ de los casos, nosotros observamos que su toxicidad es sólo ocasional, en el 5\% de los casos, lo que nos indujo a creer que el flujo menstrual no contiene tal toxina. El endometrio recogido en el primer día de la menstruación e inyectando a ratas nunca originó reacción tóxica. Opinamos que la muerte del $5 \%$ de las ratas tras la inoculación de sangre de menstruación se puede atribuir a infección. Cada muestra de flujo menstrual que ha estado en contacto con la vagina está contaminada principalmente con Streptococcus hemolyticus, Staphylococcus aureus, y Bacterium coli. Logramos cultivar de la sangre del corazón de ratas en agonía por la inyección de flujo menstrual tóxico, las mismas bacterias presentes en éste. Además, si se inyectan penicilina y estreptomicina a las ratas tratadas con flujo menstrual tóxico se mantienen vivas, mientras que las de control que no reciben antibióticos mueren. De todos modos, en nuestros estudios la sangre de menstruación resultó no ser tóxica en el $95 \%$ de los casos, pero si a veces era tóxica se podía evitar la muerte con la ayuda de antibióticos. Mi opinión es que no hay prueba de la existencia de una toxina específica ya sea en el endometrio o en el flujo menstrual.

\section{La hemorragia menstrual}

¿Cómo se inicia la menstruación? Existen numerosas teorías como explicación, pero la más conocida es la de Edgar Allen, que sugiere que la caída del nivel estrogénico inicia el desprendimiento del endometrio con la hemorragia consiguiente. Hace varios años demostramos (Zondek y Rozin) que la hemorragia 
se produce no sólo por la supresión del estrógeno sino también de la progesterona, y si durante el período postmenstrual se inyectan $10 \mathrm{mg}$. diarios de pregesterona durante cinco días consecutivos se produce una hemorragia intracíclica durante el periodo intermenstrual, que a las mujeres les parece ser idéntico a la menstruación. Del mismo modo $50 \mathrm{mg}$. de progesterona pueden provocar una hemorragia en mujeres con amenorrea. y estas pérdidas se pueden originar con progesterona en sucesión rápida, aún tres en un mes. Mi método simplificado del tratamiento de la amenorrea con progesterona, que traduce el flujo después de dos inyecciones, se basa en las observaciones precedentes. Por consiguiente, el descenso del nivel de la progesterona también induce la hemorragia endometrial. Zuckerman y Krohn han logrado el mismo efecto con desoxicórticosterona en macacos rhesus, y por lo tanto hay varias hormonas esteroides cuya disminución o supresión activa el mecanismo de la hemorragia.

Es interesante que tanto el flujo intracíclico como el logrado con progesterona en las afectas de amenorrea provenga de un endometrio en la fase proliferativa sin que en ningún caso la mucosa muestre algún signo de secreción. Las arterias espirales no están bien desarrolladas en la mucosa muy delgada, y me parece dudoso que en la hemorragia provocada con progesterona el mecanismo siga las modalidades descritas por Markee en sus bien conocidas observaciones sobre los transplantes intraovulares del endometrio. Se recordará que Kaiser al estudiar los monos sudamericanos halló que en la hembra del gibón se produce flujo menstrual a pesar de que sus vasos espirales están muy deficientemente desarrollados; ésta es la especie más pequeña de antropoide. Hisaw me mostró experimentos en antropoides con fístulas endometriales en los que logró inducir hemorragia local instilando progesterona en un sitio determinado. Sobre la base de estas observaciones me parece que las hormonas esteroides son capaces de provocar hemorragia en cualquier vaso uterino y en cualquier sitio. Según Kaiser los vasos espirales del endometrio son importantes principalmente para la implantación del embrión y no para la menstruación. No puedo decir si este concepto tan amplio de Kaiser es correcto, pero es indudable que la hemorragia puede provenir de un endometrio delgado que sólo contiene glándulas en la fase de proliferación, carece de glicógeno, y tiene vasos apenas desarrollados. 
Ahora deseo demostrar que el flujo uterino puede producirse también habiendo nivel constante de hormona, es decir, sin disminución de la hormona.

Se sabe que las hemorragias funcionales uterinas en la mujer (metropatía hemorrágica) son causadas por hiperestrinismo resultante de un folículo persistente que a veces puede alcanzar el volumen de un puño y hemos tenido la oportunidad de practicar laparotomías en tales casos con indicaciones especiales (mioma. etc.) al comienzo de la hemorragia, encontrándose intacto el folículo persistente con contenido de estrógeno de alrededor de 4 unidades laucha por centímetro cúbico. El endometrio mostraba hiperplasia quística glandular, y la determinación cuantitativa de la hormona estrógena en la orina no presentaba ningún cambio en comparación con los días precedentes, de modo que hay hemorragia producida en la mucosa con hiperproliferación sin ningún cambio en la eliminación de hormona, es decir, hemorragia sin disminución de hormona.

Durante varios años hemos estado tratando con implantaciones intravaginales de pellets de estrógeno a las mujeres afectadas de amenorrea primaria o secundaria prolongada, y semanas después de tales implantaciones se puede determinar objetivamente el efecto de la acción del estrógeno, sobre todo por el desarrollo del útero y la proliferación del endometrio antes atrófico, mediante el frotis vaginal positivo y la secreción abundante de moco cervical. De repente se produce hemorragia aunque el día anterior no se haya observado ningún cambio en la excreción de estrógeno determinado por dosificación biológica o por el método fotoflurométrico, o en la secreción de moco cervical; poco antes de que se produzca la hemorragia este moco secado en un portaobjeto revela la formación típica de abundantes cristales (arborización). Al comienzo de la hemorragia la biopsia muestra la mucosa proliferada o generalmente hiperproliferada (hiperplasia quística glandular), de modo que se trata de hemorragia proveniente del endometrio hiperproliferado sin disminución aparente de estímulo del desarrollo estrógeno.

En resumen se puede decir lo siguiente: Dado que la hemorragia puede originarse en tan diversas fases del desarrollo del endometrio, con diferentes grados de vascularización y con nivel hormónico decreciente o constante, el mecanismo no puede ser igual en cada caso de hemoragia, y al buscar un factor común se puede caer en la tentación de suponer que uno o más metabolitos 
del grupo de hormonas esteroides (especialmente estradiol y progesterona) es capaz de producir hemorragia por acción local en los vasos sanguíneos, cualquiera sea la fase del desarrollo de éstos y del endometrio.

\section{Hemorragia en conejas}

¿Puede inducirse hemorragias en animales cuyo ciclo de ordinario carece de ellas, es decir, en un ciclo sin hemorragia? Yo puedo dar respuesta afirmativa a esta pregunta sobre la base de experimentos en conejas. Durante la fase de proliferación logramos inducir el cuadro clásico de la menstruación, inclusive la hemorragia que socava la mucosa uterina, el desprendimiento del epitelio del endometrio, y el paso de la sangre al útero y a la vagina. Este efecto se puede obtener mediante la inyección diaria por vía endovenosa de $100 \mathrm{U}$. R. de prolán (gonadotropina de orina de embarazada) durante cinco días. Como el experimento no tiene éxito en animales castrados, se llega a la conclusión de que la hemorragia es inducida por vía del ovario. La progesterona carece de efecto, pero en cambio la inyección de hormona estrógena (únicamente por vía endovenosa) es capaz de inducir flujo menstrual en la coneja ¿¿Obra la hormona per se o estimula alguna otra glándula para producir la hemorragia? En colaboración con el doctor Greep, de la Universidad de Harvard se realizaron experimentos en conejas hipofisectomizadas y en otras después de la extirpación de las suprarrenales, y en ambos casos fue posible inducir hemorragia por inyección de estrona por vía endovenosa, lo que demuestra que ni la hipófisis ni las suprarrenales son esenciales para el mecanismo de la hemorragia inducida por estrona. A este respecto es interesante que Edgar Allen haya efectuado experimentos semejantes con antropoides, comprobando que la hormona estrógena no requiere ninguna sustancia auxilar para producir hemorragia.

\section{Ovulación}

El episodio más importante del ciclo sexual es la ovulación, puesto que sin ella la fecundación es imposible. Después de nuestro descubrimiento de la función gonadotrópica y de la hormona ganodotrópica del lóbulo anterior de la hipófisis consideramos que el problema de la ovulación en la mujer sería resuelto porque es posible inducir sin dificultad la ovulación con gonadotropina en varios animales de experimentación. En la rata de poca 
edad logramos inducir la ovulación y comprobar la presencia de óvulos en los tubos tras la inyección por vía subcutánea de gónadotropina. Esto mismo se puede lograr fácilmente en la coneja mediante la inyección por vía endovenosa de gonadotropina. Si se implantan trocitos (de 0,05-0,1 g.) de hipófisis anterior de vaca en una ratona preñada se puede producir ovulación durante la preñez con paso de óvulos a los tubos. Con estos resultados positivos es sorprendente que no podamos producir ovulación en los primates mediante la hormona gonadotrópica o si se logra es con dificultad. Parece que las dosis grandes de hormona gonadotrópica han logrado éxito en algunos casos según las investigaciones de Westman quien consignó resultados notables tras el tratamiento de la amenorrea con gonadotropina coriónica cristalina (36.000 U. I. por vía endovenosa durante tres días). Rydberg asegura que se puede producir la ovulación en la mujer después del tratamiento con $15.000 \mathrm{U}$. R. de gonadotropina coriónica sérica, seguido del tratamiento con $3.000 \mathrm{U}$. R. de gonadotropina coriónica urinaria. Nosotros logramos producir cuatro cuerpos lúteos en un ovario empleando gonadotropina coriónica urinaria (26.500 U. R.). Empero, los resultados que se obtienen con la gonadotropina son muy inconstantes y son tantos los autores que los niegan que el efecto de ésta en la ovulación de la mujer debe considerarse todavía discutible. Además, el objeto del tratamiento no es lograr sólo el estímulo del ovario sino iniciar la función rítmica de la hormona gonadotrópica en el lóbulo anterior de la hiófisis.

Consideramos que la hormona estrógena es la reguladora del ciclo ovárico, obrando el nivel de esta hormona de manera semejante al nivel de mercurio del regulador de un termómetro, de modo que las dosis pequeñas de estrógeno ponen en marcha el motor y las dosis grandes lo hacen parar. Si bien es fácil lograr la inhibición de la hipófisis anterior por medio de dosis grandes de estrógeno, la estimulación experimental es sumamente difícil y sólo se puede realizar con dosis pequeñas de estrógenos. Es importante que la hormona sea absorbida constantemente y que ejerza efecto continuo en la hipófisis anterior, lo que no se realiza cuando la hormona se inyecta, pues en este caso la reabsorción es seguida de inactivación enzimática rápida en el hígado. Deanesly y Parkes comprobaron que la reabsorción continua se obtenía cuando se implantan pellets de hormona, pues sólo del 1 al $5 \%$ se absorbía diariamente cuando se empleaba este método. Nosotros logramos la estimulación de la hipófisis anterior en ratas y co- 
nejas mediante la implantación de pellets de estrógeno, y en consecuencia la reproducción de hormona de crecimiento, gonadotrópica, lactotrópica y, en otros experimentos, de tirotrópica. Para empezar con el efecto mencionado en último término fue posible reproducir el síndrome humano de Graves en animales de laboratorio, exhibiendo las conejas pérdida de peso, irritabilidad nerviosa, aumento de la tasa del metabolismo basal, cambios electrocardiográficos típicos y exoftalmía externa. Además fueron producidos animales gigantescos con glándulas mamarias enormemente agrandadas, secreción de leche notablemente aumentada. e hipertrofia ovárica con desarrollo pronunciado de tejido luteínico, de manera que resultó posible, mediante pequeñas dosis continuas de hormono estrógenas, estimular la secreción de varios factores hormonotrópicos del lóbulo anterior de la hipófisis.

Sobre la base de estos resultados experimentales hemos intentado estimular la función del lóbulo anterior de la hipófisis en las mujeres también, mediante la acción continua de la hormona estrógena, y como los ensayos con inyecciones resultaron igualmente insatisfactorios, recurrimos a la implantación de pellets que parece promisoria. Hemos ensayado la implantación de la manera usual, subcutánea o intramuscular, en la parte susperior del muslo o en la pared abdominal, pero los resultados así obtenidos no fueron satisfactorios. La eficacia de éste método varía de un caso a otro, probablemente porque las pellets implantadas en el tejido subcutáneo fueron fácilmente encapsuladas tornándose así inactivas por la formación fibrosa, cuya intensidad varía en cada caso. Se comprobó experimentalmente que la actividad de la hormona estrógena aumentaba mucho cuando se inyectaba cerca del órgano indicado, es decir, en la submucosa vaginal. La dosis de estrona que se requiere para conseguir estro por vía intravaginal es de solo un quinto de las necesarias para la subcutánea y la intramuscular, y por lo tanto elegimos la implantación de' pellets por vía vaginal.

Deseo mencionar brevemente la cuestión de la dosificación que es de suma importancia para que el tratamiento logre éxito Nuestros mejores resultados los obtuvimos con pellets que contenían $20 \mathrm{mg}$. de benzoato de estradiol cada una. Con una dosificación exclusivamente elevada (60 mg.) la estimulación periférica del endometrio puede ser tan violenta que produzca hemorragia profusa y aún peligrosa. La dosis debe determinarse sobre la base del estado clínico individual, y la preparación de las pellets 
(*) para implantación es importante porque la absorción depende de la dureza de las mismas.

Es difícil juzgar los resultados de la terapéutica en mujeres con ciclos anovulatorios porque se sabe que por razones desconocidas la ovulación puede originarse repentinamente en ellas. Las mujeres sanas con menstruación regular no tienen ovulación en cada ciclo, de modo que puede suceder que mujeres con ciclos anovulatorios durante muchos meses tengan a veces ovulación. Por consiguiente hemos realizado nuestras investigaciones en casos de amenorrea tanto primitiva como secundaria de larga duración (tres años, y en la mayoría de los casos cinco a ocho años).

No es necesario que entre en detalles, pues lo que interesa ahora es la circunstancia de que en varios casos de máximo trastorno funcional tuvimos éxito con una sola o con repetidas implantaciones intravaginales de estrógeno en pellets, logrando no sólo restablecer el ciclo normal sino también producir ovulación con el consiguiente embarazo, lo que se puso de manifiesto sobre todo en siete casos de amenorrea primitiva con atrofia acentuada de los órganos genitales y úteros apenas palpables. Estos casos que se consideraban deshauciados en la era anterior a las hormonas fueron restablecidos plenamente y culminaron en el embarazo. Los mismos resultados, es decir, inducción de la ovulación y embrazo, fueron logrados en varios casos (13) de amenorrea secundaria entre las cuales había uno con francos signos viriles (Clitoris muy agrandado, hirsutismo y atrofia del útero y del endometrio) que se destacó especialmente.

Estos hallazgos demuestran que la resorción continua de estrógenos es capaz de producir funcionamiento rítmico del ovario por medio del lóbulo anterior de la hipófisis y, lo que es más importante, de originar ovulación con la posible consecuencia de embarazo.

\section{Relación entre las mucosas uterina y vaginal}

Los trabajos muy conocidos de Papanicolau y Schorr han demostrado que en la mujer el epitelio de la vagina sufre cambios clínicos y que se puede diagnosticar la función ovárica por medio de frotis vaginales. Por muy fundamentales que estas observaciones puedan ser hay que considerarlas con cierta reserva, lo que

(*) Se obtuvieron los mejores resultados con bolitas facilitadas gentilmente por N. V. Organon, Oss. Holanda. 
deseo ilustrar con un ejemplo. En años recientes hemos simplificado aún más el tratamiento de la amenorrea en cuanto que podemos inducir el flujo menstrual con una inyección, lo que es posible por la inoculación de un precipitado de estrona y progesterona, o sean microcristales. Disponemos de dos preparaciones, en una la precipictación se efectúa en la jeringa al mezclarse las hormonas con suero fisiológico, y en la otra, la precipitación tiene lugar después de aplicarse la inyección en el tejido al mezclarse con el líquido de éste. El flujo menstrual comienza en la amenorréicas luego de un intervalo de diez a doce días, y hemos comprobado que después de la inyección de los precipitados ambas fases aparecen en el frotis vaginal, primero, la fase estrógena que dura hasta el quinto día después de la inyección y es seguida de la fase progestacional con su cuadro típico al noveno día, lo que significa que el mismo cuadro anatómico se produce en el epitelio de la vagina, como en una mujer poco antes de empezarle la menstruación. Sobre la base del frotis vaginal uno tendría que llegar a la conclusión de que el endometrio está en la fase progestacional y de que por lo tanto la ovulación ha tenido lugar. Empero, el examen del endometrio demuestra que lo contrario es la realidad. La hemorragia se produce en una mucosa delgada en la fase proliferante, es decir, en la que precede a la ovulación. circunstancia que se debe tener en cuenta antes de sentar el diagnóstico sobre la base de los frotis vaginales. Cuando podemos seguir los cambios característicos de la fase lútea en los frotis vaginales es posible inferir que la progesterona es producida en el ovario, pero no podemos suponer con certeza que el endometrio está en su fase progestacional. Parece que se requieren dosis más pequeñas de hormonas para inducir cambios funcionales en la mucosa vaginal que en el endometrio. La técnica del frotis vaginal puede a veces inducirnos a diagnosticar una fase progestacional cuando en realidad la mucosa uterina no se encuentra en el estado funcional correspondiente. Nuestras observaciones sugieren una discrepancia de respuesta entre las mucosas vaginal y uterina. En consecuencia no se debe descuidar el examen anatómico de la mucosa uterina en favor del frotis vaginal, lo que implica menosprecio de la importancia de éste sino que simplemente se destaca la circunstancia de que la secreción vaginal no es siempre el espejo del estado de la función de la mucosa uterina. 


\section{Una substancia fluorogénica en la orina humana}

Finalmente deseo referirme a nuestras investigaciones recientes.

La hormona estrógena puede demostrarse por el método bien conocido de Allen y Doisy empleándose frotis vaginales de ratas o ratonas castradas. Desde hace mucho tiempo se ha procurado reemplazar este método biológico por un químico. El método colorimétrico de Kober es bien conocido, pero es más adecuado para los ensayos cualitativos que para los cuantitativos. Wieland, Strub y Dorfmueller observaron que los estrógenos producen una fluorescencia verdosa cuando son calentados con ácido sulfúrico concentrado. Hace varios años Finkelstein, Hestrin y Kock crearon en mi laboratorio y publicaron un método fotoflurométrico para la determinación cuantitativa de estradiol, estrona y estriol, que también adaptamos para el examen de orina. Varios meses después Bates y Cohn así como Jailer describieron experimentos similares en los Estados Unidos, y ahora muchos laboratorios han adoptado el método fluorométrico para la determinación de los estrógenos. Para este análisis son suficientes 10 milímetros de orina, y se puede determinar una cantidad tan pequeña como de 20 a $30 \mathrm{mg}$. o aún menos, por litro. En nuestro laboratorio las pruebas se realizan con el fluorómetro de Farrand. Opino que el método fotofluorométrico representa un adelanto notable. Nos sorprendió observar que la determinación fluorométrica de estradiol en la orina de hombres y de mujeres sanos producía titulaciones sumamente elevadas en el análisis de orina según el método de Bachman y Pettit; los valores eran mucho más altos que los observados en bioensayos según Allen y Doisy. Fue razonable suponer que en la extracción de la orina alguna sustancia fluorescente adicional es llevada a la fracción de estriol produciendo así valores excesivos inexactos de estriol. Hemos examinado numerosas muestras de orina de gente sana y de afectos de trastornos endocrinos; sin embargo, en éstos las diferencias entre los valores obtenidos por el método fluorométrico y por bioensayos no eran lo suficientemente notables para justificar el intento de separar el estriol de la otra sustancia fluorescente hipotética. Nos convencimos por el caso de una chica de once años de edad con signos típicos de seudohermafroditismo; tenía el aspecto de un joven de veinte, timbre varonil de voz, y crecimiento de barba como varón; el clitoris se le había transformado en falo de 7 centímetros de 
largo. Varios años antes se le había extirpado la cápsula suprarrenal izquierda muy aumentada y que demostró una hiperplasia. El cuadro clínico permaneció inalterado por la operación. Le practiqué una laparotomía a esta chica para determinar si había presencia de ovotestis, y observé órganos genitales femeninos, útero y ovarios con un folículo que contenía hormona estrógena; no se halló tejido testicular ni tampoco del semejante al suprarrenal. En la orina observamos diez veces más de la excreción normal de lgs 17 cetosteroides ( $68 \mathrm{mg}$. en venticuatro horas), en tanto que los corticosteroides se hallaron sólo ligeramente aumentados.

En el análisis del contenido de estriol de su orina por el método fluorométrico obtuvimos un valor ocho veces mayor que con la prueba de Allen-Doisy; esta orina nos pareció especialmente adecuada para intentar la separación de la sustancia fluorogénica no idéntica al estriol proveniente de estriol, y logramos éxito procediendo de la manera siguiente: Cuando la orina hidrolizada es agitada con éter y luego se extraen con $\mathrm{NaOH}$ las sustancias estrógenas, la sustancia fluorogénica permanece en la fracción de éter. Este resultó un método conveniente para separar de los estrógenos la sustancia fluorogénica desconocida. Por lo tanto, las hormonas estrógenas, que son fenoles, podrían extraerse con $\mathrm{NaOH}$, mientras la sustancia desconocida queda en la fracción neutral en éter.

Se realizó purificación adicional brevemente, como sigue: El residuo del éter se colocó en una mezcla de benzol y éter de petróleo. La sustancia desconocida se puede extraer de esta mlezcla con agua. Fue extriado otra vez de la solución acuosa con éter, se limpió nuevamente con alcohol metílico y tetracloruro de carbono, y se traspasó a alcohol para determinación fluorométrica.

De este modo entramos en posesión de una sustancia separable de la hormona estrógena, pero que muestra fluorescencia tal como la hormona estrógena cuando se calienta con ácido fosfórico. ¿Dónde se puede encontrar esta sustancia? Según nuestros estudios lo que se sabe es lo siguiente: La sustancia, expresada en términos de 17-hidroxi-córtico-esterona, se halla presente en toda orina humana en pequeñas cantidades al rededor de 1,5 mg. por litro en los varones, y de $1 \mathrm{mg}$. en las mujeres; su titulación se duplica durante el tiempo de la ovulación. Durante los últimos meses del embarazo puede observarse un considerable aumento de la titulación, aproximadamente tres a cuatro veces más de lo normal. En dos casos de seudohermafroditismo femenino fue obser- 
vada la titulación más alta, cinco a seis veces más de lo normal. La excreción de la sustancia se elevó en la orina después de una inyección de ACTH y bajó tras la administración de cortisona.

En colaboración con el profesor T. Reichstein en Basilea aislamos de la orina de seudohermafroditas femeninas una sustancia fluorogénica y establecimos su estructura como 3, 17, 20 pregnanetriol, 11-uno. Este esteroide no habia sido hasta entonces aislado de ninguna fuente natural, ni su presencia había sido indicada.

Como la excreción de pregnanetriol-uno se aumenta especiátmente en los trastornos adrenogenitales graves, es probable que la sustancia provenga de las cápsulas suprarrenales. El cálculo cuantitativo de esta sustancia (pregnanetriol-uno) puede ser útil en el diagnóstico del seudohermafroditismo, lo que se puede demostrar en el caso siguiente. El sujeto de ventiún años de edad se consideraba varón y usaba ropa masculina, su timbre de voz era varonil, pero su cara barbilampiña; tenía pene pequeño sin escroto; se palpaba un testículo en el canal inguinal derecho; el hipogastrio estaba ocupado por un gran tumor. En la laparatomia encontré órganos genitales femeninos completamente desarrollados, útero de tamaño normal cuya mucosa estaba en la fase de escreción inicial; le faltaban los anexos del lado izquierdo En el lado derecho tenía una trompa dura u ocuida y un ovario con cuerpo lúteo en función. Además hallamos un tumor quístico en el ovario del tamaño de la cabeza de una criatura, lleno de una masa semejante a chocolate, de modo que el hallazgo consistió de un útero, un ovario en función y un gran tumor ovárico. El material extraído del testículo en el canal inguinal contenía células interticiales de Leidig bien desarrolladas y en cambio los túbulos seminíferos contenian sólo células de Sertoli y espermatogonia. Este era un caso de hermafroditismo verdadero. Son relativamente raros los casos de hermafroditismo verdadero, y en la literatura se han descrito sólo 44. Los casos como el que acabo de describir, con gran tumor ovárico (quiste con masa semejante a chocolate originado por endometriosis), han sido al parecer rara vez observados. La orina de este caso tenía título sumamente bajo, subnormal, de pregnanetriol-uno, sólo $0,3 \mathrm{mg}$. por litro, y en cambio la excreción era cinco veces mayor de lo normal en casos de seudohermafroditismo femenino. El hermafroditismo verdadero no se acompaña de hiperfunción de las cápsulas suprarrenales.

En dos casos de seudohermafroditismo masculino con testículos y órganos genitales femeninos también encontramos la ex- 
creción de pregnanetriol-uno dentro de límites normales, es decir, sin aumento como en el seudohermafroditismo femenino. Por lo tanto es posible hacer el diagnóstico diferencial entre el seudohermafroditismo femenino, el seudohermafroditismo masculino y el hermafroditismo verdadero sobre la base del contenido de pregnanetriol-uno y los 17 cetosteroides.

La valoración cuantitativa del pregnanetriol-uno parece preferible a la determinación de los 17 cetosteroides como ayuda en el diagnóstico del síndrome adrenogenital, porque en muchos casos de hirsutismo y ligero virilismo, que clínicamente no eran comparables con el estado de seudohermafroditismo, encontramos excreción aumentada de los 17 cetosteroides, pero excreción normal de pregnanetriol-uno.

A pesar de que la presencia de grandes cantidades de pregnanetriol-uno en la orina de casos de hiperplasia suprarrenal acentuada, y la reducción de su excreción bajo la influencia de la cortisona pueden arrojar alguna luz sobre la naturaleza del desorden en el metabolismo esteroide en esta afección, nos abstenemos por ahora de enunciar una teoría relativa a la formación de pregnanetriol-uno.

Un nuevo hallazgo es siempre el comienzo de un nuevo problema, pero esta perpetuidad es después de todo la fascinación de la investigación en medicina. 